\title{
UNI-SOFT QUASI-HYPERIDEALS OF ORDERED SEMIHYPERGROUPS
}

\author{
Muhammad FAROoQ \\ Department of Mathematics \\ Abdul Wali Khan University Mardan \\ 23200, Khyber Pakhtunkhwa, Pakistan \\ Government Higher Secondary School Mohib Banda Mardan \\ 23200, Khyber Pakhtunkhwa, Pakistan \\ e-mail: farooq4math@gmail.com \\ RAEES KHAN \\ Department of Mathematics \\ FATA University \\ Darra Adam Khel, N.M.D. Kohat, KP, Pakistan \\ e-mail: raeeskhan@fu.ed.pk \\ AsGHAR KHAN \\ Department of Mathematics \\ Abdul Wali Khan University Mardan \\ 23200, Khyber Pakhtunkhwa, Pakistan \\ e-mail: asghar@awkum.edu.pk \\ AND \\ MUHAMMAD IZHAR \\ Department of Mathematics \\ Government College Garhi Kapura Mardan \\ 23200, Khyber Pakhtunkhwa, Pakistan \\ e-mail: mizharmath@gmail.com
}

\begin{abstract}
The main purpose of this article is to study ordered semihypergroups in the context of uni-soft quasi-hyperideals. In this article, using the notion of soft-union sets in ordered semihypergroups, we introduce the concept of union-soft (uni-soft) quasi-hyperideal and the related properties
\end{abstract}


are investigated. We prove that every uni-soft left (right) hyperideal is a uni-soft quasi-hyperideal but the converse is not true which is shown with help of an example. We present the characterizations of left (right) simple and completely regular ordered semihypergroups in terms of uni-soft quasihyperideals. Furthermore we define semiprime uni-soft quasi-hyperideal and characterize completely regular ordered semihypergroup using this notion.

Keywords: uni-soft bi-hyperideal, uni-soft quasi-hyperideal, semiprime unisoft quasi-hyperideal, left (right) simple, regular and completely regular ordered semihypergroup.

2010 Mathematics Subject Classification: 20N20.

\section{REFERENCES}

[1] T. Changphas and B. Davvaz, Bi-hyperideals and Quasi-hyperideals in ordered semihypergroups, Italian J. Pure Appl. Math.-N 35 (2015) 493-508.

[2] P. Corsini and V. Leoreanu-Fotea, Application of hyperstructure theory (Advanced in Mathematics, Kluwer Academic Publisher).2003

[3] B. Davvaz, Fuzzy hyperideals in semihypergroups, Italian J. Pure Appl. Math.-N 8 (2000) 67-74.

[4] B. Davvaz, Weak algebraic hyperstructures as a model for interpretation of chemical reactions, Int. J. Math. Chemistry 7 (2016) 267-283.

https://doi.org/10.22052/ijmc.2016.13975

[5] B. Davvaz, A.D. Nezhad and M.M. Heidari, Inheritance examples of algebraic hyperstructures, Inform. Sci. 224 (2013) 180-187.

https://doi.org/10.1016/j.ins.2012.10.023

[6] M. Farooq, A. Khan, R. Khan and M. Izhar, Characterization of ordered semihypergroups in terms of uni-soft bi-hyperideals, Journal of Algebraic Hyperstructures and Logical Algebras (2020) Inpress.

[7] F. Feng, M.I. Ali and M. Shabir, Soft relations applied to semigroups, Filomat 27 (2013) $1183-1196$. https://doi.org/10.2298/FIL1307183F

[8] Y.B. Jun, S.Z. Song and G. Muhiuddin, Concave soft sets, critical soft points, and union-soft ideals of ordered semigroups, The Scientific World Journal 2014 (1-11) Article ID 467968.

[9] Y.B. Jun, K.J. Lee and A. Khan, Soft ordered semigroups, Math. Logic Quarterly 56 (2010) 42-50. https://doi.org/10.1002/malq.200810030

[10] N. Kehayopulu, On Left Regular Ordered Semigroups, Math. Japon. 35 (1990) 10571060.

[11] N. Kehayopulu and M. Tsingelis, Regular ordered semigroups in terms of fuzzy subsets, Inform. Sci. 176 (2006) 3675-3693. https://doi.org/10.1016/j.ins.2006.02.004 
[12] N. Kehayopulu, On Completely Regular Ordered Semigroups, Sci. Math. 1 (1998) $27-32$.

[13] A. Khan, R. Khan and Y.B. Jun, Uni-soft structure applied to ordered semigroups, Soft Comput. 21 (2017) 1021-1030. https://doi.org/10.1007/s00500-015-1837-8

[14] A. Khan, Y.B. Jun, S.I.A. Shah and R. Khan, Applications of soft union sets in ordered semigroups via uni-soft quasi-ideals, J. Intell. Fuzzy Syst. 30 (2016) 97-107. https://doi.org/10.3233/IFS-151734

[15] A. Khan, M. Farooq and H. Khan, Uni-soft hyperideals of ordered semihypergroups, J. Intell. Fuzzy Sys. 35 (2018) 4557-4571. https://doi.org/10.3233/JIFS-161821

[16] A. Khan, M. Farooq and B. Davvaz, Characterizations of ordered semihypergroups by the properties of their intersectional-soft generalized bi-hyperideals, Soft Comput. 22 (2018) 3001-3010. https://doi.org/10.1007/s00500-017-2550-6

[17] A. Khan, M. Farooq and N. Yaqoob, Uni-soft structures applied to ordered $\Gamma$ semihypergroups, Proc. of the Nat. Acad. of Sci., India Section A: Phys. Sci. 90 (2020) 457-465. https://doi.org/10.1007/s40010-019-00602-x

[18] F. Marty, Sur Une generalization de la notion de group, $8^{\text {iem }}$ congress, Math. Scandinaves Stockholm (1934) 45-49.

[19] D. Molodtsov, Soft set theory - first results, Comput. Math. Appl. 37 (1999) 19-31. https://doi.org/10.1016/S0898-1221(99)00056-5

[20] S. Naz and M. Shabir, On prime soft bi-hyperideals of semihypergroups, J. Intell. Fuzzy Sys. 26 (2014) 1539-1546. https://doi.org/10.3233/IFS-130837

[21] B.O. Onasanya, A Note on Hyperstructres and Some Applications, International J. Math. Combin. 4 (2017) 60-67.

[22] B. Pibaljommee and B. Davvaz, Characterizations of (fuzzy) bi-hyperideals in ordered semihypergroups, J. Intell. Fuzzy Sys. 28 (2015) 2141-2148. https://doi.org/10.3233/IFS-141494

[23] B. Pibaljommee, K. Wannatong and B. Davvaz, An investigation on fuzzy hyperideals of ordered semihypergroups, Quasigroups and Related Systems 23 (2015) 297-308.

[24] M. Shabir and A. Khan, Fuzzy Quasi-Ideals of Ordered Semigroups, Bull. Malays. Math. Sci. Soc 34 (2011) 87-102. https://doi.org/10.20454/ijas.2012.424

[25] J. Tang, A. Khan and Y.F. Luo, Characterization of semisimple ordered semihypergroups in terms of fuzzy hyperideals, J. Intell. Fuzzy Sys. 30 (2016) 1735-1753. https://doi.org/10.3233/IFS-151884 
[26] J. Zhan, N. Čă̆man and A.S. Sezer, Applications of soft union sets to hemirings via SU-h-ideals, J. Intell. Fuzzy Sys. 26 (2014) 1363-1370.

https://doi.org/10.3233/IFS-130822

Received 3 March 2020

Revised 13 September 2020

Accepted 16 September 2020 